\title{
DETECÇÃO DE ANTICORPOS IgM NAS INFECÇÕES PRIMÁRIAS E SECUNDÁRIAS PELO CITOMEGALOVÍRUS EM PACIENTES SUBMETIDOS A TRANSPLANTE RENAL
}

\author{
Claudio Sergio PANNUTI (1), Lucy Santos VILAS BOAS (1), Vicente AMATO NETO (1), \\ Maria José de Oliveira ANGELO (2) \& Emil SABB AGA (3)
}

\section{R E S U M O}

Foram acompanhados 27 pacientes submetidos a transplante renal para avaliação do comportamento dos anticorpos IgM e IgG CMV-específicos.

Dos 27 casos estudados, $17(63,0 \%)$ tinham anticorpos IgG, detectados pela reação de fixação de complemento (RFC), antes de serem submetidos ao transplante, e $10(37,0 \%)$ eram soro negativos. A pesquisa de anticorpos IgM (técnica de imunofluorescência indireta) foi negativa em todas as amostras pré-transplante. Num período de acompanhamento que variou de 28 a 425 dias (média de 115 dias) após o transplante, observou-se que 20 dos $27(74,1 \%)$ apresentaram evidências sorológicas de infecçāo pelo CMV, ocorrendo a maioria dos casos $(14 / 20,70 \%)$ em pacientes que já tinham anticorpos para o CMV antes do transplante. A pesquisa de anticorpos IgM CMV-específicos foi positiva em 12 dos 14 pacientes com evidências sorológicas de reinfecção ou reativação da infecção pelo $\mathrm{CMV}$, e em 100\% (6/6) dos pacientes com infecção primária. Dentre os 10 pacientes acompanhados por mais de 4 meses, somente $1(10 \%)$ negativou o IgM neste período.

UNITERMOS: Anticorpos IgM anti-citomegalovírus; Infecçōes primárias e secundárias; Transplante Renal.

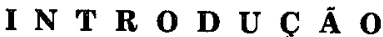

Numerosos estudos, publicados nas últimas 2 décadas, tem demonstrado a importância da infecçāo pelo citomegalovírus (CMV) nos pacientes submetidos a transplante renal ${ }^{8,13}$. Estas infecçōes podem ocorrer tanto em indivíduos sem exposição prévia ao $\mathrm{CMV}$, caracterizando portan to uma infecção primária, quanto em pacientes que já possuiam anticorpos para o CMV antes de receber o rim transplantado. Neste último caso, admite-se que a reativação de infecção la- tente desencadeada pela imunossupressão à qual o paciente é submetido no período póstransplante seria o principal mecanismo envolvido. Entretanto, a possibilidade da existência de mecanismos adicionais como a reinfecção exógena pelo CMV, a partir do rim transplantado ou adquirida através de transfusōes de sangue ou contacto com outros indivíduos infectados, não está afastada.

(1) Instituto de Medicina Tropical de São Paulo: Laboratórios de Investigaçāo Médica HC FMUSP. Av. Dr. Eneas de Carvalho Aguiar, 470. 05403 Sāo Paulo, SP - Brasil.

(2) Instituto de Ciências Biomédicas da Universidade de Sāo Paulo.

(3) Unidade de Transplante Renal do Hospital das Clínicas da Faculdade de Medicina da Universidade de São Paulo. 


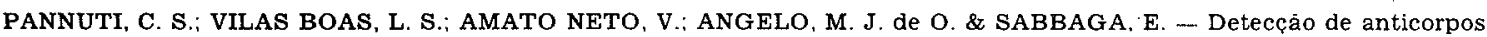
IgM nas infecçōes primárias e secundárias pelo citomegalovirus em pacientes submetidos a transplante renal. Rev. Inst. Med. trop. São Paulo, 29:317-322, 1987.

As infeç̧ões podem ser totalmente assintomáticas ou apresentarem-se com quadro clínico discreto. Contudo, uma parcela dos pacientes infectados apresenta doença disseminada, grave, que pode levar ao óbito ${ }^{8,13}$.

Vários estudos tem indicado que, nos pacientes com transplante renal, a infecção primária associa-se mais freqüentemente à doença sintomática e complicaçōes secundárias do que a reativação 3. 4. 14, 29. 30. A caracterização de uma infecção primária não apresenta dificuldades quando se dispõe de amostra de sangue prétransplante. Todavia, quando o estado imunitário prévio é desconhecido, a diferenciação laboratorial entre infecção primária e reativação ou reinfecção torna-se difícil.

Em indivíduos imunocompetentes, a detecção de anticorpos de classe IgM específicos para o CMV, através da reação de imunofluorescência indireta (IFI $)^{10,19}$, técnica imunoenzimática ${ }^{24}$ ou radioimunoensaio ${ }^{16,18,25}$, apresenta-se como alternativa de grande valor para o diagnóstico da infecção primária, aguda. Nestes pacientes, o IgM aparece sistematicamente na fase aguda da infecção e tem duração limitada a alguns poucos meses, de modo que sua presença sempre indica infecçāo recente pelo $\mathrm{CMV}^{16,19}$ Contudo, em pacientes submetidos a transplante renal, alguns estudos demonstraram que os anticorpos IgM CMV-específicos podiam ser detectados em casos bem documentados de reativação de infecções latentes, pré-existentes ${ }^{20,22,26}$. Nestes pacientes, a detecção de IgM anti-CMV em amostra isolada de sangue não poderia distinguir uma infecção primária de uma reativação. Estes achados porém, não foram confirmados por outros pesquisadores ${ }^{16}$.

O objetivo do presente estudo é avaliar, em pacientes submetidos a transplante renal, o comportamento dos anticorpos IF IgM em relação ao estado imunitário pré-transplante, procurando estabelecer sua capacidade em discriminar as reativações e as infecções primárias pelo CMV.

\section{MATERIAL E MÉTODOS}

\section{A. Casuistica}

Foram estudados 27 pacientes submetidos a transplante renal na Unidade de Transplante
Renal do Hospital das Clínicas, da Faculdade de Medicina da Universidade de São Paulo no período de 1972 a 1974 . Estes pacientes foram estudados anteriormente no sentido de se verificar a incidência de infecção pelos vírus do Her pes simplex (VHS), vírus de Epstein-Barr (VEB) e $\mathrm{CMV}^{23}$. A idade dos pacientes, na época do transplante, variou de 09 a 54 anos (média $=$ 26,8 ), sendo 14 do sexo masculino e 13 do sexo feminino. Todos foram submetidos à imunossupressāo após o transplante, com prednisona e azathioprina, conforme esquema descrito em detalhes na referida publicaçāo ${ }^{23}$.

\section{B. Coleta de amostras de soro e seguimento}

Os pacientes foram acompanhados por períodos que variaram de 28 a 425 dias (média de 115 dias) após o transplante. Neste período, obteve-se uma amostra de sangue pré-transplante de todos os pacientes, e uma a 6 amostras no período pós-transplante (média de 3,4 por paciente). Os soros foram mantidos congelados a $-20^{\circ} \mathrm{C}$.

\section{Reaçōes sorológicas}

Em todas as amostras colhidas foram dosados anticorpos para o vírus de Epstein-Barr, para o virus do Herpes simplex e para o citomegalovírus.

Em relação ao VEB foram pesquisados anticorpos IgG anti-capsídeo viral (anti-EBVCA) pela técnica de imunofluorescência indireta de HENLE \& HENLE ${ }^{12}$ usando-se como fonte de antígeno o clone PeHR1 da linhagem Jijoye. Para o vírus do Herpes simplex também foi usada a imunofluorescência indireta, servindo como fonte de antígeno a amostra Mc Intyre do VHS tipo I, inoculado em células Vero.

Para o citomegalovírus, empregou-se, para detecção de anticorpos IgG, a técnica de fixação do complemento (FC) com $50 \%$ de hemólise e como antígeno a amostra Ad 169 (Flow); para detecção de anticorpos IgM empregou-se a técnica da imunofluorescência (IF-IgM) servindo como fonte de antígeno a amostra Ad 169 do CMV mantida em culturas de células diplóides de fibroblastos de prepúcio obtidos a partir de crianças postectomizadas. $O$ conjugado anti-IgM hu- 
PANNUTI, C. S.; VIlas BoAs, L. S.: AMATo NETO, V.: ANGELO, M.J. de O. \& SABBAGA, E. - Detecçào de anticorpos IgM nas infecçōes primárias e secundárias pelo citomegalovirus em pacientes submetidos a transplante renal. Rev. Inst. Med. trop. Sâo Paulo, 29:317-322, 1987.

mano foi obtido comercialmente (Hyland Diagnostics).

Em todas as amostras de soro pesquisou-se a presença do fator reumatóide através do teste do látex. Nas amostras de soro com teste do látex positivo e pesquisa de anticorpos IF-IgM-CMV também positiva, procedeu-se à absorção do fator reumatóide com suspensão de partículas de látex sensibilizadas com IgG humana. Após a negativação do teste do látex, repetia-se a pesquisa de anticorpos IF-IgM CMV-específicos, sendo consideradas positivas somente as amostras que apresentavam títulos $\geqslant 5$ após a absorção do fator reumatóide ${ }^{28}$. Em relação à $\mathrm{RFC}$, considerou-se como positivas as amostras com titulos $\geqslant 4$, e para a reação de IF anti-EBVCA e anti-VHS títulos $\geqslant 10$.

\section{RESULTADOS}

Dos 27 casos estudados, $17(63,0 \%)$ tinham anticorpos FC presentes antes de serem submetidos ao transplante renal e $10(37,0 \%)$ eram soronegativos.

Utilizando-se a combinação das reacões de FC e pesquisa de IgM anti-CMV pela imunofluorescência indireta pode-se constatar evidência sorológica de infecção pelo CMV em $20(74,1 \%)$ dos 27 pacientes estudados.

O comportamento dos anticorpos FC e anticorpos IgM anti-CMV nos casos de infecção primária e nas reativações das infecções pelo CMV pode ser observado na Tabela I.
O tempo de acompanhamento dos pacientes após o transplante renal foi muito variável (1 a 14 meses). Contudo, dentre os 10 pacientes com IF-IgM anti-CMV positiva que puderam ser acompanhados por mais de 4 meses, somente $1(10,0 \%)$ negativou o IgM durante o período de observaçāo.

Anticorpos IgG anti-EBVCA estavam presentes em todas as 27 amostras pré-transplante. Em nenhuma das amostras houve aumento sig. nificativo dos títulos após o transplante.

Em relação ao vírus do Herpes simplex, das 27 amostras pré-transplante testadas, observouse presença de anticorpos IgG em $23(85,2 \%)$. Nas amostras pós-transplante não se observou variação significativa dos títulos em nenhum dos casos. Os 4 pacientes soronegativos, não apresentaram sóroconversão durante o acompanhamento.

A pesquisa do fator reumatóide foi positiva em 6 dos 27 pacientes estudados $(32,3 \%)$. Todos os 6 eram pacientes que apresentaram evidências sorológicas de infecção primária (1/6) ou reativaçāo (5/6) de infecção pelo CMV, com pesquisa IgM anti-CMV positiva. Contudo, em nenhum deles houve negativação dos anticorpos IgM específicos para o CMV após a absorçāo do fator reumetóide.

\section{DISCUSSĀO}

A demonstraçāo de infecção pelo CMV em $74,1 \%$ dos 27 pacientes estudados no presente

Comportamento dos anticorpos FC e IF-IgM CMV- específicos em 27 pacientes submetidos a transplante renal

\begin{tabular}{|c|c|c|c|}
\hline & \multicolumn{3}{|c|}{ Anticorpos FC anti-CMV antes do transplante } \\
\hline 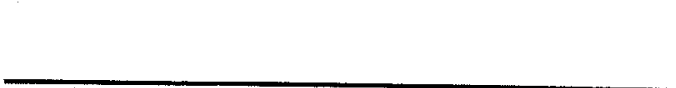 & $\begin{array}{l}\text { N: }(\%) \text { positivos } \\
\quad(n=17)\end{array}$ & $\begin{array}{l}\text { No }(\%) \text { negativos } \\
\quad(\mathbf{n}=10)\end{array}$ & $\begin{array}{l}\text { № }(\%) \text { total } \\
(\mathbf{n}=\mathbf{2 7})\end{array}$ \\
\hline IgM + pré-transplante & 0 & $\mathbf{0}$ & 0 \\
\hline $\begin{array}{l}\text { Aumento significativo do título de anticorpos FC } \\
\text { pós-transplante }\end{array}$ & $12(70,6)$ & $5(50,0)$ & $17(63,0)$ \\
\hline Positivaçāo do IgM anti-CMV pós-transplante & $12(70,6)$ & $6(60,0)$ & $18(66,7)$ \\
\hline $\begin{array}{l}\text { Evidências sorológicas de infecçâo nos primeiros } 60 \text { dias } \\
\text { pós-transplante }\end{array}$ & $9(52,9)$ & $4(40,0)$ & $13(48,1)$ \\
\hline $\begin{array}{l}\text { Evidências sorológicas de infecçāo nos primeiros } 90 \text { dias } \\
\text { pós-transplante }\end{array}$ & $13(76,5)$ & $6(60,0)$ & $19(70,4)$ \\
\hline Total das infecçōes (FC + IgM) & $14(82,3)$ & $6(60,0)$ & $20(74,1)$ \\
\hline
\end{tabular}


PANNUTI, C. S., VILAS BOAS, L. S.; AMATO NETO, V.; ANGELO, M. J. de O. \& SABBAGA, E. - Detecçào de anticorpos IgM nas infecçōes primárias e secundárias pelo citomegalovírus em pacientes submetidos a transplante renal. Rev. Inst. Med. trop. Säo Paulo, 29:317-322, 1987.

trabalho está de acordo com as taxas observadas por numerosos investigadores que estudaram prospectivamente pacientes submetidos a transplante renal. Nestes estudos as incidências de infecção pelo CMV variaram de $43 \%$ a $92 \%$, com média de $75 \%$.

A maioria das infecções, tanto nos pacientes com infecção primária quanto nos pacientes previamente soropositivos, ocorreu nos primeiros 3 meses pós-transplante (Tabela I). Estes achados são concordantes com as observações de outros pesquisadores $3,7,15,26,29,30$.

Com poucas exceçōes, houve concordância entre o aumento de anticorpos FC e aparecimento de anticorpos IgM CMV-específicos. Contudo, constatou-se casos em que a infecção só foi evidenciada pelo IgM e outras em que houve au mento do título de anticorpos FC e o IgM permaneceu negativo (Tabela I). Observa-se também que entre os pacientes infectados, a maioria $(14 / 20,70 \%)$ já tinham anticorpos FC para o CMV antes do transplante, configurando portanto uma reativação. Todavia, a possibilidade de ocorrência de reinfecção não pode ser afastada. Em pacientes submetidos a transplante de medula estudos de epidemiologia molecular demonstraram que a infecção pós-transplante ocorre fundamentalmente por reativaçāo de vírus já presentes antes do transplante ${ }^{31}$. A maior freqüência de infecção pelo $\mathrm{CMV}$ em pacientes previamente soropositivos neste e em outros trabalhos ${ }^{8}$ sugere que no transplante renal o mecanismo de reativaçāo também deve ser o mais importante.

A presença do fator reumatóide, que é um anticorpo IgM anti-IgG humano inespecífico, tem sido apontado como causa de reaçōes falso positivas na pesquisa de anticorpos $\operatorname{IgM}^{28}$. Nesta casuística, embora estivesse presente em 6 dos 18 casos com pesquisa de anticorpos IgM antiCMV positiva, em nenhum houve modificação dos resultados após absorção do fator reumatóide. Por outro lado, a possibilidade de reações cruzadas com anticorpos resultantes de infecçāo pelo vírus de Epstein-Barr. ${ }^{11}$ também foi afastada no presente trabalho, já que nenhum dos 27 pacientes estudados apresentou evidência de infecçāo aguda pelo EBV.
Relatos anteriores ${ }^{20.26}$ demonstrando que, em pacientes submetidos a transplante renal $e$ posterior imunodepressão, a detecçāo de IgM anti-CMV em amostras de sangue isoladas não permite a diferenciação entre infecção primária e reativação de infecção pré-existentes foram confirmados pelos resultados obtidos no presente trabalho. Isto pode ser claramente observado na Tabela I pelo aparecimento destes anticorpos em $70,6 \%$ dos pacientes com infecção prévia pelo CMV antes do transplante renal, caracterizando desta forma mecanismos de reativação ou reinfecçāo. Por outro lado, nos pacientes susceptíveis que apresentaram infecção primária pelo CMV no periodo pós-transplante, estes anticorpos foram detectados em todos os casos.

Diferindo do que ocorre em pacientes imunocompetentes, os anticorpos. IF-IgM CMV pecíficos nos pacientes imunodeprimidos perduram por muitos meses ${ }^{26}$. Isto pode ser constatado na presente série, já que dentre os 10 pacientes com IgM positivo que puderam ser acompanhados por mais de 4 meses, somente em $1(10 \%)$ o exame se negativou. Por isso; ao serem detectados num paciente transplantado, estes anticorpos não permitem, isoladamente, determinar com segurança a época em que ocorreu a infecção.

A demonstração recente de drogas antivirais com atividade "in vivo" contra o CMV, tais como DHPG ${ }^{2,5,6,21,27}$ e o Foscarnet ${ }^{1,17}$, trouxeram novas perspectivas para o controle desta infecção nos imunodeprimidos. Contudo, nos pacientes submetidos a transplante renal, as diferenças na intensidade e gravidade dos sintomas observados nas infecções primárias e nas reinfecções ou reativaçōes de infecções latentes torna muito importante, nos protocolos de estudo destes antivirais, separar estas formas de infecção. $O$ presente trabalho demonstra que a deteç̧ão de anticorpos IgM CMV-especificos não pode ser utilizada isoladamente com esta finalidade.

\section{SUMMARY}

Specific IgM antibodies in primary and secundary cy tomegalovirus infections after renal transplantation 
PANNUTI, C. S.; VIlAs BoAs, L. S.; AMATO NETO, V.; ANGELO, M. J. de O. \& SABBAGA, E. - Deteccào de anticorpos IgM nas infecçóes primárias e secundárias pelo citomegalovirus em pacientes submetidos a transplante renal. Rev. Inst. Med. trop. São Paulo, 29:317-322, 1987.

Twenty-seven patients who underwent renal allograft transplants were periodically screened for the presence of IgM and IgG cytomegalovirus (CMV) antibodies.

Before transplantation, 17 (63\%) had IgG an tibodies by complement fixation and $10(37 \%)$ were seronegative. Immunofluorescent IgM CMV-antibodies were absent in all pre-transplant sera.

During a follow-up period of 28 to 425 days (median of 115 days), 20 (74\%) developed serologic evidence of CMV infection. Of these, $6(30 \%)$ were primary and $14(70 \%)$ secondary (reactivation or reinfection). IF-IgM antibodies were seen in 12 out of 14 patients with secondary CMV infection and in all patients with primary infection.

IgM antibodies became negative in one out of 10 IgM-positive patients who were followed-up for 4 months or more.

\section{REFERÊNCIAS BIBLIOGRÁFICAS}

1. APPERLEY, J. F.; MARCUS, R. E.; GOLDMAN, J. M.; WARDLE, D. G.; GRAVETT, P. J. \& CHANAS, A. - Foscarnet for cytomegalovirus pneumonitis. Lancet, 1: 1151, 1985.

2. BACH, M. C.; BAGWELL, S. P.; KNAPP, N. P.; DAVIS, K. M. \& HEDSTROM, P.S. - 9-(1,3-dihydroxy-2-propoxymethyl) guanine for acquired immunodeficiency syndro. me. Ann. Intern. Med., 103: 381-382, 1985.

3. BETTS, R. F.; FREEMAN, R. B.; DOUGLAS JR., R. G. \& TALLEY, T. E. - Clinical manifestations of renal allograft derived primary cytomegalovirus infection. Amer. J. Dis. Child., 131: 759-763, 1977.

4. CHATTERJEE, S. N.; FIALA, M.; WEINER, J.; STEWART, J. A.; STACEY, B. \& WARNER, N. - Primary cytomegalovirus and opportunistic infections. Incidence in renal transplant recipients. J. Amer. med. Ass., 240: 2446-2449, 1978.

5. COLLABORATIVE DHPG TREATMENT STUDY GROUP - Treatment of serious cytomegalovirus infections with 9-(1, 3-dihydroxy-2- propoxymethyl) guanine in patients with AIDS and other immunodeficiencies. New Eng1. J. Med., 314: 801-805, 1986.

6. FELSENTEIN, D.; D'AMICO, D. J.; HIRSCH, M. S.; NEUMEYER, D. A.; CEDERBERG, D. M.; MIRANDA, P. \& SCHOOLEY. R. T. - Treatment of cy tomegalovirus reti- nitis with 9- \2-hydroxy-1- (hydroxymethyl) ethoxymethyl guanine. Ann. intern. Med., 103: 377-380, 1985.

7. FRYD, D. S.; PETERSON, P. K.; FERGUSON, R. M.; SIMMONS, R. L.; BALFOUR JR., H. H. \& NAJARIAN, J.S. - Cytomegalovirus as a risk factor in renal transplantation . Transplantation, 30: 436-439, 1980.

8. GLENN, J. - Cytomegalovirus infections following renal transplantation. Rev. infec. Dis., 3: 1151-1178, 1981.

9. HANSHAW, J. B.; NIEDERMAN, J. C. \& CHESSIN, L. N. - Cytomegalovirus macroglobulin in cell-associated herpevirus infections. J. infect. Dis., 125: 304-306, 1972.

10. HANSHAW, J. B.; STEINFELD, H. J. \& WHITE, C. J. - Fluorescent-antibody test for cytomegalovirus macroglobulin. New Engl. J. med., 279: 566-570, 1968.

11. HEKKER, A. C.; BRAND-SAATHOF, B.; VIS, J. \& MEIJERS, R.C. - Indirect immunofluorescence test for detection of IgM antibodies to cytomegalovirus. J. infect. Dis., 140: 596, 600, 1979.

12. HENLE, G. \& HENLE, W. - Immunofluorescence in cells derived from Burkitt's lymphoma. J. Bact., 91: 1248-1256, 1966.

13. HO, M. - Human cytomegalovirus infections in immunosupressed patients. In: HO, M. - Cytomegalovirus: biology and infection. New York, Plenum Medical Book Company, 1982. p. 171-204.

14. HO, M.; SUW ANSIRIKUL, S.; DOWLING, J. N.; YOUNGBLOOD , L. A. \& ARMSTRONG, J. A. - The transplanted kidney as a source of cytomegalovirus infection. New Engl. J. Med., 293: 1109-1112, 1975.

15. IANHEZ, L. E.; SARTURI, P. S.; PAULA, F. J. \& SABBAGA, E. - Infecçāo por citomegalovírus pós-transplante renal. Rev. Hosp. Clín. Fac. Med. S. Paulo, 39: 47-53, 1984.

16. KANGRO, H. O. - Evaluation of a radioimmunoassay for IgM-class antibodies against cytomegalovirus. Brit. J. exp. Path., 61: 512-520, 1980.

17. KLINTMALM, G.; LONNQVIST, B.; OBERG.; GAHRTON, G.; LERNESTEDT, J-O.; LUNDGREN, G.; RINGDEN, O.; ROBERT, K-H.; WAHREN, B. \& GROTH, C-G. - Intravenous foscarnet for the treatment of severe cytomegalovirus infection in allograft recipients. Scand. J. infect. Dis., 17: 157-163, 1985.

18. KNEZ, V.; STEWART, J. A. \& ZIEGLER, D. W. - Cytomegalovirus specific IgMand IgG response in humans studies by radioimmunoassay. J. Immunol., 117: 2006-2013, 1976.

19. LANGEHUYSEN, M. M. A. C.; THE, T. H.; NIEWEG, H. O. \& KAPSENBERG, J. G. - Demonstration of IgM cytomegalovirus antibodies as an aid to early diagnosis in adults. Clin. exp. Immunol., 6: 387-393, 1970. 
PANNUti, C. S.; Vilas boAs, L. S.; AMATo Neto, V.; ANGELO, M. J. de O. \& SABBAgA. E. — Detecçāo de anticorpos IgM nas infecçóes primárias e secundárias pelo citomegalovírus em pacientes submetidos a transplante renal. Rev. Inst. Med. trop. São Paulo, 29:317-322, 1987.

20. LINNEMANN JR., C. C.; DUNN, C. R.; FIRST, M. R.; AL VIRA, M. \& SCHIFF, G. M. - Late onset of fatal cytomegalovirus infection after renal transplantation. Arch. intern. Med., 138: 1247-1250, 1978.

21. MASUR, H.; LANE, H. C.; PALESTINE, A.; SMITH, P. D.; MANISCHEWITZ, J.; STEVENS, G.; FUJIKAWA, L.; MACHER, A. M.; NUSSENBLATT, R.; BAIRD, B.; MEGILL, M.; WITTEK, A.; QUINNANN, G. V.; PARRILLO, J. E.; ROOK, A. H.; ERON, L. J.; PORETZ, D. M.; GOL. DENBERG, R. I.; FAUCI, A. S. \& GELMANN, E. P. Effect of 9 (1,3-dihydroxy-2-propoxymethyl) guanine on serious cytomegalovirus disease in eight immunosuppressed homosexual men. Ann. intern. Med., 104: 41-44, 1986.

22. NAGINGTON, J. - Cytomegalovirus antibody production in renal transplant patients. J. Hyg. (Lond.), 69: 645-660, 1971.

23. PANNUTI, C. S.; CARVALHo, R. P. S.; AMATO Neto , V.; SABBAGA, E. \& ANGELO, M. J. O. - Infecçōes por vírus do grupo Herpes em pacientes submetidos a transplante renal. Rev. Inst. Med. trop. S. Paulo, 20: 353-358, 1978.

24. PanNuti, C. S.; STEWren, K. E.; CARValho, R. P. S.; MIRANDA, M. N.; ANGELO, M. J. O.; VILAS BOAS, L. S. \& AMATO NETO, V. - síndrome "mononucleose simile" na infáncia. Incidência da infecçāo por citomegalovírus diagnosticado através da detecção imunoenzimática de anticorpos IgM. Rev. Inst. Med. trop. S. Paulo, 25: 300-304, 1983.

25. PANNUTI; C. S., VIlas BoAs, L. S.; ANGELO, M. J. O.; AMATO NETO, V.; LEVI, G. C.; MENDONÇA, J. S. \& GODOY, C. V. F. - Cytomegalovirus mononucleosis in children and adults differences in elinical presentation. Scand. J. infect. Dis., 17: 153-156, 1985.

26. PASS, R. F.; GRIFFITHS, P. D. \& AUGUST, A. M. Antibody response of cytomegalovirus after renal transplantation: comparison of patients with primary and re current infections. J. infect. Dis., 147: 40-46, 1983.

27. SHEP, D. H.; DANDLIKER, P. S.; MIRANDA, P.; BUR NETTE, T. C.; CEDERBERG, D. M.; KIRK, L. E. \& MEYERS, J. D. - Activity of 9-2-hydroxy-1-(hydroxymethyl) ethoxymethyl guanine in the treatment of cytomegalovirus pneumonia. Ann. intern. Med., 103: 368-373, 1985.

28. SHIRODARIA, P. V.; FRASER, K. B. \& STANFORD, F. - Secondary fluorescent staining of virus antigens by rheumatoid factor and luorescein-conjugated anti-IgM. Ann. rheum. Dis., 32: 53-57, 1973.

29. SPENCER, E: S. - Clinical aspects of cytomegalovirus infection in kidney-graft recipients. Scand. J. infect. Dis., 6: 315-323, 1974.

30. SUWANSIRIKUL, S.; RAO, N.; DOWLING, J. N. \& HO M. - Primary and secondary cytomegalovirus infection. Clinical manifestations after renal transplantation. Arch. intern. Med., 137: 1026-1029, 1977.

31. WINSTON, D. J.; HUANG, E-S.; MILLER, M. J.; LIN, C-H.; HO, W. G.; GALE, R. P. \& CHAMPLIN, R. E. - Molecular epidemiology of cytomegalovirus infections associated with bone marrow transplantation. Ann. intern. Med., 102: $16-20,1985$.

Recebido para publicaçāo em 08/07/87. 